\title{
Kümelenmenin Sürdürülebilirlik Uygulamalarına Etkisi: Türkiye Mermer İşletmelerine Yönelik Bir Araştırma \\ The Effect of Clustering on Sustainability Practices: A Study on Turkish Marble Enterprises
}

\author{
Özlem TUNA \\ Afyon Kocatepe Üniversitesi \\ Afyon Sağlık Yüksek Okulu \\ Afyonkarahisar, Türkiye \\ ozltuna@hotmail.com
}

\section{Özet}

$\mathrm{Bu}$ çalışmada işletmelere pek çok konuda üstünlük sağlayan kümelenmenin, çevresel, sosyal ve ekonomik boyutlara sahip sürdürülebilirlik uygulamalarına etkisinin belirlenmesi amaçlanmıştır. Bu doğrultuda, 4562 sayılı Organize Sanayi Bölgeleri Kanunu'na göre küme olarak kabul edilen İscehisar İhtisas Organize Sanayi Bölgesi'nde (OSB) faaliyet gösteren 45 mermer işletmesine ve her hangi bir kümenin üyesi olmayan ve çeşitli illerde faaliyet gösteren 34 mermer işletmesine yönelik anket uygulaması gerçekleştirilmiştir. Araştırmada, betimsel istatistiklerin yanı sıra iki grup arasındaki farklılıklar $t$ testi ile analiz edilmiştir. Araştırma sonucunda, küme üyesi olan KOBİ niteliğindeki işletmelerin, çevreye olumsuz etkilerin azaltılması ve sosyal performansın artırılması yönündeki uygulamaların pek çoğunu küme üyesi olmayan işletmelere göre daha etkili bulduğu tespit edilmiştir.

Anahtar Kelimeler: Kurumsal sürdürülebilirlik, kurumsal sürdürülebilirlik uygulamaları, kümelenme, KOBİ

\section{Abstract}

This study aims to identify the influence of clustering, which provides advantage to establishments in many aspects, on sustainability practices with environmental, social and economic dimensions. Accordingly, a survey was conducted on 45 marble establishments operating in Iscehisar Specialized Organized Industrial Zone (OIZ), which is deemed to be a cluster pursuant to the Law no. 4562 on Organized Industrial Zones, as well as 34 marble establishments, which are not members of any cluster and operate in various provinces. During the study, besides descriptive statistics, differences between two groups were analyzed with $t$ test. At the end of the study, it was established that most practices of establishments with SME characteristics, which were members of a cluster, intended for reducing negative influences on the environment and increasing social performance, were more effective than establishments, which were not members of a cluster.

Keywords: Corporate Sustainability, corporate sustainability practices, cluster, SME 


\section{Giriş}

Ülkemiz mermer sektörü, Türkiye toplam madencilik ihracatının yaklaşık \%50'sini karş1layarak en büyük payı sahiptir. 2014 yılında ham, kabaca yontulmuş veya blok mermer, toplam maden ihracatımız içinde en fazla ihraç edilen ürün olurken, işlenmiş mermer ikinci sırada yer almaktadır (İMMİB, 2015, s. 5). Ayrıca ülkemiz için stratejik bir öneme sahip olan sektör, üretim değeri, istihdama sağladığı katk1, ihracatı ve dış ticareti karşılama oranıyla ülkemizin en önemli sektörlerinden biridir. Her türlü inşaat projesinin tamamlayıcısı ve inşaat sektörünün en gözde girdilerinden olan mermer, son yıllarda inşaat sanayinde ortaya konulan büyük atılımlar ve bu gelişmenin sürdürüleceğine dair göstergeler nedeniyle önümüzdeki dönemde de yükselen grafiğini sürdüreceği yönündeki beklentileri arttırmaktadır. Bu durum, mermer işletmelerine ürün kalitesi ve güvenliği, insan sağlı̆̆ı, çevre kirliliği, kaynakların tükenmesi, atık oluşturma, çalışanların sağlık ve güvenliğinin sağlanması gibi sürdürülebilirliğin sosyal ve çevresel boyutlarını ilgilendiren konularda önemli görevler yüklemektedir.

Çevresel, sosyal ve ekonomik boyutlara sahip sürdürülebilirlik, işletmelerin risk ve firsatları anlayabilmesi ve buna göre faaliyetlerini, ürün ve hizmetlerini, gerektiğinde iş modellerini ve tüm süreçlerini yeniden düzenlemesi anlamına gelmektedir. Sürdürülebilirlik yönündeki bu düzenlemeler, işletmelerin ciddi sermaye ve uzmanlık yatırımı yapmasını, uzun vadeli iş planlarına sahip olmasını ve sürdürülebilirliğe ilişkin dilin anlaşılabilmesi için yönetici ve çalışan eğitimlerini gerektirmektedir. Uzun zaman ve çaba gerektiren sürdürülebilirlik, işletmelere coğrafi, kültürel ve kurumsal yakınlık, diğer işletmelere özel erişim, daha yakın ilişkiler, bilgiye kolay erişim, güçlü teşvikler elde etme gibi üstünlükler sağlayan kümelenme (Has, 2013, s.2) ile daha da kolaylaşabilmektedir. Bu nedenle kümelerin ana paydaşı olan KOBİ'lerin özelliklerini anlama ve sürdürülebilir kalkınma için yeterliliklerinin artırılması önemli hale gelmiştir.

OECD verilerine göre tüm işletmelerin \%95'ini ve çalışanların yaklaşık \%60'nı oluşturan KOBI'lerin iyi yönetilmeleri ve sağlıklı bir yapıya sahip olmaları; sosyal istikrar ve genel vergi gelirlerine yaptıkları katkıdan dolayı istihdam ve refah için önemli bir kaynak olarak görülmektedir (WBCSD, 2004, s. 2). Ülkemizde faaliyet gösteren toplam 2.406.720 işletmenin, \%99,6's1 Avrupa Birliği KOBİ tanımına uygun ${ }^{1}$ büyüklüktedir. $\mathrm{Bu}$ işletmelerden madencilik ve taşocakçıllı̆ 1 faaliyet kolunun işyeri başına çalışan kişi sayısı (ortalama ölçek büyüklüğü) 34,3'tür (Bayülken ve Kütükoğlu, 2012, s. 16). Araştırmaya konu olan işletmelerin \%83.6'sı bu veriyi destekler nitelikte küçük ve orta ölçekli işletmelerden oluşmaktadır. Bu nedenle çalışmayla küme üyesi olan ve olmayan KOBİ niteliğindeki mermer işletmelerinin kurumsal sürdürülebilirlik uygulamalarına yaklaşımlarının belirlenmesi amaçlanmıştır. $\mathrm{Bu}$ çerçevede, İscehisar İhtisas OSB'inde faaliyet gösteren ve küme üyesi olan ve her hangi bir kümenin üyesi olmayan, çeşitli illerde faaliyet gösteren KOBİ niteliğindeki toplam 79 mermer işletmesine yönelik nicel yöntemle araştırma yapılmıştır.

\footnotetext{
${ }^{1}$ Araştırmada 18 Kasım 2005 tarih ve 25997 sayılı Resmi Gazetede yayımlanan ve 18 Mayıs 2006 tarihinde yürürlüğe giren "Küçük ve Orta Büyüklükteki İşletmelerin Tanımı, Nitelikleri ve Sınıflandırılması Hakkında Yönetmelik" le getirilen KOBİ tanımlaması esas alınmıştır. Tanımlamaya göre, 1-9 işçi çalıştıran mikro işletme, 1049 işçi çalıştıran kü̧̈ük işletme ve 50-249 işçi çalıştıran ise orta ölçekli işletme olarak tarif edilmiştir.
} 


\section{Kümelenme Kavramı}

Sürdürülebilir kalkınma, insanoğlunun birim aileden geniş toplumlara kadar refah düzeyinin arttırılması yönündeki kalkınma çabalarını, ekonomik, sosyal ve çevresel boyutlarıyla dikkate alıp, gerekli kalkınma stratejilerini takip etmek, bunu yaparken gelecek kuşaklarında en az bugünkü toplumlarla eşit kaynaklara sahip bir şekilde kalkınmasının sağlanabileceği koşulların yaratılmasına çalışmaktır (Gürlük, 2010, s. 88). Temel odak noktası çevre, toplum ve ekonomik kalkınma olan sürdürülebilir kalkınmanın sağlanması (Pelit, Baytok ve Soybalı, 2015, s.42), yerel ve bölgesel kalkınmanın gerçekleşmesine bağlıdır. Bu nedenle birçok ülkede merkezi, bölgesel ve/veya yerel idareler, işletmelerin endüstriyel faaliyetlerini belli bir bölgede yoğunlaştırmaları için bölgenin gelişmesini amaçlayan bütüncül yaklaşımlar geliştirmiştir. $\mathrm{Bu}$ doğrultuda 1990'ların sonundan bu yana bölgelerin yetenek ve dinamiklerini ortaya çıkarmada küme geliştirme yaygın olarak kullanılan bir strateji halini almıştır. 2008 yılında Science Business Innovation Board tarafından açıklanan verilere göre AB'de 2000'i aşkın kümelenme ve 70 farklı ulusal kümelenme politikası bulunmaktadır. AB ve OECD gibi ulusal ve bölgesel politika yapıcı kuruluşlar KOBİ'ler için küme gelişimini, küme içindeki işletmelerin ve diğer örgütlerin yakınlığından sağlanan sinerji ve koordinasyondan yararlanma şeklinde tanımlamışlardır (Eroğlu ve Yalçın, 2013, s.179). Porter ise kümeleri, işletmeler ve kurumların birbirleri ile ilişkilerinin belli bir bölgede coğrafik yoğunlaşması olarak ifade etmiştir. Kümeler bağlantılı endüstrilerin ve rekabette önemli yeri olan diğer girişimlerin birlikteliğini kapsamaktadır. Bunlar makine, hizmet ve uzmanlaşmış alt yapı sağlayıcıları gibi özel girdilerin tedarikçilerini içermektedir. Ayrıca birçok kümede üniversiteler, standart belirleme kuruluşları, mesleki eğitim kurumları, ticari birlikler ve düşünce kuruluşları gibi hükümet ve diğer kurumlar birlikte çalışmaktadır (Porter, 1998). Genel olarak kümelenme, ulusal ya da bölgesel düzeyde, rekabetçiliğin arttırılması, yenilikçiliğin ve Ar-Ge faaliyetlerinin teşvik edilmesi, bölgesel bazda kalkınmanın hızlandırılması, yabancı yatırımların çoğaltılması ve KOBİ'lerin desteklenmesi gibi faydalar sağlamaktadır (Yardımcı, 2014, s. 25). Ayrıca kümelenme, küçük ölçekli işletmelere büyük işletmeler gibi üretimlerinde ölçek ekonomilerinden yararlanabilme firsatı verirken aynı zamanda bu üretim ağları daha esnek üretim sistemleri oluşturarak işbirliğine dayalı inovasyon ve karşılıklı öğrenmeyi desteklemektedir (Chang, Tsai, Henderson, 2012, s. 6).

\section{Kobi’lerde Kurumsal Sürdürülebilirlik}

KOBI'ler büyük işletmelerle yaptıkları ortaklıklar sayesinde global ekonomiye katılmakta böylece ülke ekonomilerinin gelişiminde önemli bir rol oynamaktadırlar. Ancak KOBİ'lerin çevresel ve sosyal konulara duyarlılıkları zaman, para, insan kaynağı vb. konularda yaşadıkları sıkıntılar nedeniyle, istenilen seviyelere ulaşamamaktadır. KOBİ'lerin bu sıkıntıların üstesinden gelmesi ve sürdürülebilirlik konularına duyarlılıklarının artması hükümetlerin, sivil toplumun ve büyük ölçekli işletmelerin katkısı ile mümkündür. Sıralanan kurum ve kuruluşların desteğini alan KOBİ'ler, insan hakları, işgücü politikaları, çevresel uygulamalar ve güvenlik gibi sürdürülebilir uygulamalarda başarılı olabilecek ve böylece ekonomik büyüme, çevrenin iyileştirilmesi ve sosyal ortamın geliştirilmesine önemli katkılar sağlayacaklardır. 


\section{Kobi’lerde Kurumsal Sürdürülebilirlik Uygulamaları}

Hükümet politikaları, düzenleyici kural baskıları, tüketici istekleri ve tedarik zinciri baskıları (ACCA, 2010, s.27) KOBİ'leri sürdürülebilirlik uygulamalarını kendi faaliyet ve iş süreçlerine entegre etmeye zorlamaktadır. Ancak zaman yetersizliği, finansal kaynak ve kalifiye personel eksikliği KOBI'lerin sürdürülebilirlik uygulamalarında büyük ölçekli işletmelere göre daha düşük bir performans göstermesine neden olmaktadır (Jeppesen vd., 2012, s. 45). Bahsi geçen zorluklara rağmen, KOBİ'lerin sürdürülebilirlik yönünde yürüttüğü uygulamaları, raporlama faaliyetleri ve çevresel ve sosyal uygulamalar olmak üzere iki başlıkta toplamak mümkündür.

\subsection{Raporlama Faaliyetleri}

Sürdürülebilirlik yaklaşımı uygulama, raporlama, denetim ve belgelerin global standartlarda gelişimini gerektirmektedir. Yaklaşımın önemli bir ayağı olan sürdürülebilirlik raporlaması KOBİ'lere rekabet avantajı, iç süreçlerin geliştirilmesi ve amaç saptama başarısı; itibar, güven ve saygının geliştirilmesi gibi önemli faydalar sağlamaktadır. Raporlamanın KOBİ'lere önemli katkıları bulunmasına rağmen, KOBİ'lerin sürdürülebilirlik standartları üzerinde çok az etkisi bulunmakta ve global sürdürülebilirlik raporlama standartları bu işletmelere odaklanmamaktadır (ACCA, 2010, s. 27).

\section{2. Çevresel ve Sosyal Uygulamalar}

Günümüzde çoğu araştırma çevre ile ilgili stratejiler ve bu stratejilerin uygulanmasına odaklanmıştır. Sürdürülebilirliğin sosyal boyutu hakkında KOBI'lere yönelik çok az sayıda çalışma yapıldığı ve çalışmaların da özellikle kurumsal sosyal sorumluluk konusu üzerinde yoğunlaştığı görülmektedir (Foot ve Ross, 2004; Sharma ve Ruud, 2003, Lawrence vd., 2006).

Dünyadaki endüstriyel kirliliğin yaklaşı \%70'ine neden olan KOBİ'ler özellikle enerji kullanımının azaltılması (1sıtma, aydınlatma, ofis donanımı, basınçlı hava kullanımı, vantilatör, pompalar, motorlu araçlar vb.); su faturalarının azaltılması; kirliliğin azaltılması; nakliye maliyetlerinin azaltılması (lojistik, araç ve yakıt seçimi) ve yasalara uyulması gibi çevre konularına odaklanmaktadır (ACCA, 2012, s. 9).

Sürdürülebilir kalkınmada önemli bir paya sahip ve toplumun ayrılmaz bir parçası olan KOBI'lerin, çevresel performanslarını geliştirmesi EMAS ve ISO 14001 gibi formal yönetim sistemlerini uygulanması ile mümkündür. $\mathrm{Bu}$ yönetim sistemleri politikalar, prosedürler ve uygulamalar aracılığıyla çevresel etkilerin kontrolünü sağlamaktadır (Hillary, 2004, s. 562).

Formal çevre yönetim araçlarının (EMAS, ISO 14001 gibi.) yanında eko-tasarım, geri dönüşüm gibi çevresel uygulamalarda KOBI'lerin artan ilgisi araştırma sonuçlarına da yansımıştır. Avrupa Komisyonu'nun 2013 yılı verileri KOBİ'lerin \%51'nin organik ürün, eko-etiketleme ve eko-tasarım gibi çevre yönetim araçlarını kullandığını, \%35'inin ise ürün ve hizmetlerinde geri dönüşüm malzemesi kullandığını tespit etmiştir (Eurobarometer, 2013, s. 85). KOBİ'lerin eko-tasarıma olan ilgisini inovasyon firsatları, ürün kalitesi ve pazar fırsatlarının artması, tüketici istekleri, hükümet düzenlemeleri ve sanayi girişimleri gibi faktörlere bağlamak mümkündür (Hemel ve Cramer, 2002, s. 439). Buna karşın geri dönüşüme ait \%35 gibi düşük bir oranın nedenini Defra'nın 2010 
yılında Londra'da yaptığı araştırmanın sonuçları açıklamaktadır. KOBİ'ler geri dönüşüm uygulamalarında bir takım engellerle karşılaşmakta ve aynı zamanda onlar için bir maliyet kalemi olan bu uygulamaya mesafeli durmaktadır. Araştırmada geri dönüşümün önündeki engeller atık dönüşüm merkezlerinin olmaması, alt yapının kurulması için sermaye ihtiyacı, KOBİ'ler için geri dönüşümün zorunlu olmaması, KOBİ'lerin bir kısmında çevre mevzuatı bilincindeki eksiklik ve bazı malzemeler için geri dönüşüm hizmetinin olmaması şeklinde belirlenmiştir (WRAP, 2011, s. 7). Sürdürülebilirliğin sosyal boyutu hakkında KOBI'lere yönelik çok az sayıda çalışma yapılmış ve bu çalışmalar, kurumsal sosyal sorumluluk konusu üzerinde yoğunlaşmıştır.

\section{Araştırmanın Amacı, Önemi ve Sınırlılıkları}

Araştırmanın amacı, her hangi bir kümenin üyesi olma/olmamanın sürdürülebilirlik uygulamalarına etkisinin belirlenmesidir. Bu genel amaç doğrultusunda bir kümenin üyesi olan ve herhangi bir kümenin üyesi olmayan iki farklı işletme grubunun kurumsal sürdürülebilirliğe bakış açılarındaki ve yaklaşımlarındaki farklılıklar tespit edilmeye çalışılmıştır.

Ulusal ve uluslararası literatürde kurumsal sürdürülebilirliğe yönelik KOBİ ve büyük ölçekli işletmeleri çalışma alanı yapan pek çok çalışma bulunmaktadır. Ancak, kurumsal sürdürülebilirlik uygulamalarında kümelenme stratejilerinin etkisini ölçecek herhangi bir çalışma olmaması araştırmanın önemini arttırmaktadır. Ayrıca, sürdürülebilirlik araştırmalarının çoğunlukla büyük ölçekli işletmelere yönelik olduğu görülmektedir. Bu çalışmanın küçük ve orta ölçekli mermer işletmelerine yoğunlaşması diğer önemli katkısı olarak görülmektedir.

İşletme yöneticilerinin gündemini giderek daha fazla meşgul eden çevresel, sosyal ve ekonomik boyutlara sahip sürdürülebilirlik anlayış1, ülkemiz işletmeleri için yeni anlam kazanmaya başlamıştır. Bu nedenle işletmelerin kavrama yönelik tüm bilgilere sahip olamaması ve konuyla ilgili öngörüde bulunamaması araştırmanın en önemli kısıtlarındandır. Kısıtlardan bir diğeri yöneticilerin sınırlı zamanıdır. Küçük ve orta büyüklükteki işletmelerde girişimci, yönetici kimliği ile doğrudan faaliyetlere katılmakta üretimden idari işlemlere kadar tüm konularla ilgilenmek zorunda kalmaktadır. $\mathrm{Bu}$ nedenle anketi cevaplandırmaları için yöneticilerden randevu talep edilmiş, buna rağmen yöneticilerin yoğun iş temposu görüşmeler sırasında engel oluşturmuştur. Araştırmanın son kısıtı ise araştırma aracının anket olmasıdır. İşletmeler için yeni bir konu olan sürdürülebilirliğe ilişkin, katılımcıların olası sorularını cevaplama ve derinlemesine bilgi sağlama imkânın olmaması, anket tekniğinin yapısal özelliklerinden kaynaklanan kısıtlar olarak belirtmek mümkündür.

\section{Yöntem}

Çalışma, İscehisar İhtisas OSB'nde ve çeşitli illerde faaliyet gösteren her hangi bir kümenin üyesi olmayan mermer ocağı sahibi ve üretimi yapan işletmelerde yapılmıştır. Sanayide verimliliği ve etkinliği artırıcı yöntemler arasında olan kümelenme yaklaşımı son yıllarda önem kazanmış ve pek çok ülkenin kalkınma programlarına alınmıştır. Bu nedenle ülkemizde de çeşitli çalışmalar yapılmış ve İhtisas OSB'leri kurularak kümelenme çalışmaları desteklenmiştir. İscehisar İhtisas OSB'de, 4562 sayılı Organize Sanayi Bölgeleri Kanun'un 4. Maddesinde sanayide kümelenme yaklaşımıyla örtüşen "Aynı sanayi iş kolunda ve bu iş koluna dâhil alt sanayi gruplarında faaliyet gösteren tesisler” tanımına uymaktadır (Resmi Gazete, 2009). Bu çerçevede, 45'i İscehisar 
İhtisas OSB'nde, 34'ü ülkemizin farklı illerinde faaliyet gösteren toplam 79 mermer işletmesiyle yapılan anketler değerlendirilmeye alınmıştır.

Çalışma Mayıs -Ekim 2015tarihleri arasında yürütülmüştür. Veri toplama metodu olarak sosyal bilimlerde hızlı bir şekilde çok sayıda veri elde etme olanağı sağladığı için oldukça yaygın olarak kullanılmakta olan anket yöntemi seçilmiştir. Anketler hem manüel formatta hem de dijital formatta hazırlanarak, İscehisar İhtisas OSB'nde faaliyet gösteren işletmelerde yüz yüze görüşme yöntemi ile yapılmış; farklı illerde faaliyet gösteren işletmelerle ise elektronik posta yoluyla geri dönüşler sağlanmıştır. Anketler, işletme içerisinde temel strateji ve işletme politikalarının uygulanmasından sorumlu icra görevine sahip üst düzey yöneticiler tarafından doldurulmuştur.

Araştırmada veri toplama tekniği olarak iki bölümden oluşan anket kullanılmıştır. Anketin ilk bölümünde işletmelerin özellikleri ve çevresel ve sosyal konulardaki durumlarını belirlemeye yönelik sorular yer alırken ikinci bölümünde çevresel ve sosyal performans ile kümelenme ilişkisine yönelik sorular yer almaktadır. Araştırmada, Hahn ve Scheermesser (2006)'in Alman işletmelerinde; Yu (2004)'nun Çin'de faaliyet gösteren KOBİ'ler üzerinde ve İMKB (2011)'nin İMKB'ye üye işletmeler ile yaptığ 1 çalışmada kullandığı ölçeklerden yararlanılarak literatür çerçevesinde sektörel uyarlama ile Tuna (2014) tarafından geçerlilik ve güvenilirlik çalışması yapılarak oluşturulan ölçek kullanılmıştır. Anketin ilk bölümünde çoktan seçmeli sorular yer alırken, çevresel ve sosyal performans ile kümelenme ilişkisine yönelik bölümünde 5'li ölçeğe göre hazırlanmış sorular yer almaktadır. Araştırmada, anket ile edilen veriler SPSS for Windows Paket Programıla analiz edilmiştir. İscehisar İhtisas OSB ve farklı illerdeki işletmeler üzerinde uygulanan anket çalışmasından elde edilen veriler çalışmanın ana taslağına göre frekans, yüzde, aritmetik ortalama, standart sapma ve t-testi (Ural ve Kılıç, 2013) gibi istatistiksel analizlere tabi tutulmuştur. Ulaşılan istatistiksel değerler karşılaştırmalı analizlerle değerlendirilerek araştırmayı temellendiren hipotezler test edilmiştir.

\section{Bulgular}

Araştırma verilerine ilişkin bulgular, işletmelerin özellikleriyle ilgili tanımlayıcı istatistikler ve işletmelerin sürdürülebilirlik uygulamaları ile kümelenme ilişkisine yönelik istatistikler olmak üzere aşağıda verilmiştir.

Tablo 1. İşletmelerin Özellikleriyle ilgili Tanımlayıcı İstatistikler

\begin{tabular}{|l|l|c|c|}
\hline \multicolumn{2}{|c|}{ İşletmelerin Özellikleri } & f & \% \\
\hline \multirow{4}{*}{ Hizmet Yılı } & $4-7$ & 12 & 15.2 \\
\cline { 2 - 4 } & $8-11$ & 14 & 17.7 \\
\cline { 2 - 4 } & $12-15$ & 16 & 20.3 \\
\cline { 2 - 4 } & 16 ve üzeri & 37 & 46.8 \\
\hline \multirow{3}{*}{ Hukuki Statü } & Anonim Şirket & 19 & 24.1 \\
\cline { 2 - 4 } & Limited Şirket & 55 & 69.6 \\
\cline { 2 - 4 } & Şahıs Şirketi & 5 & 6.3 \\
\hline \multirow{3}{*}{ Çalışan Sayısı } & $0-9$ & 13 & 16.5 \\
\cline { 2 - 4 } & $10-49$ & 33 & 41.8 \\
\cline { 2 - 4 } & $50-249$ & 33 & 41.8 \\
\hline \multirow{3}{*}{ Isletme Niteliği } & Ulusal & 17 & 21.5 \\
\cline { 2 - 4 } & Uluslararas1 & 62 & 78.5 \\
\hline \multirow{2}{*}{$\begin{array}{l}\text { Sahip Olunan Kalite Yönetim } \\
\text { Belgeleri }\end{array}$} & ISO 9001:2000 & 42 & 53.2 \\
\cline { 2 - 4 } & ISO 14001 & 7 & 8.9 \\
\cline { 2 - 4 } & OHSAS 18001 & 9 & 11.4 \\
\hline
\end{tabular}


İşletmelerin yaklaşık \%67'sinin 12 yıl ve üzerinde faaliyet gösterdikleri; \%94'nün sermaye şirketi (anonim ve limited) olduğu; \%41.8'inin küçük, \%30.4'ünün orta, $\% 11.5$ 'nin ise büyük ölçekli işletme olduğu tespit edilmiştir. Ayrıca, işletmelerin \%78.5'inin uluslararası faaliyetlerde bulunduğu; \%53.2'sinin ISO 9001 kalite belgesine, \%11.4'nün ise OHSAS 18001 belgisine sahip olduğu Tablo 1'de görülmektedir.

\section{Tablo 2. İşletmelerin Diğer Kurum/Kuruluş/İşletme(ler) ile İşbirliği İçinde} Olunan Konulara Göre Dağılımı

\begin{tabular}{|l|c|c|c|}
\hline \multicolumn{1}{|c|}{ Maddeler } & $\begin{array}{c}\text { Küme üyesi } \\
\text { olma/olmama } \\
\mathbf{f ( \% )}\end{array}$ & $\begin{array}{c}\text { Küme üyesi } \\
\text { f (\%) }\end{array}$ & $\begin{array}{c}\text { Küme üyesi } \\
\text { olmayan } \\
\text { (f) (\%) }\end{array}$ \\
\hline Çevre kirliliğinin azaltılması & $50(63,2)$ & $29(36.7)$ & $21(26.5)$ \\
\hline Yenilikçilik (inovasyon) çalışmaları & $18(22.7)$ & $14(17.7)$ & $4(0.5)$ \\
\hline Yerel halk ile ilişkiler & $25(31.6)$ & $14(17.7)$ & $11(13.9)$ \\
\hline İş sağlığı ve iş güvenliği & $73(92.4)$ & $43(54.4)$ & $30(37.9)$ \\
\hline Reklam/Halkla ilişkiler & $44(55.6)$ & $25(31.6)$ & $19(24)$ \\
\hline Su kullanımı ve yönetimi & $30(37.9)$ & $22(27.8)$ & $8(10.1)$ \\
\hline Yetişmiş insan kaynağının sağlanması & $14(17.7)$ & $11(13.9)$ & $3(0.3)$ \\
\hline Fuar Katılımı & $47(59.4)$ & $31(39.2)$ & $16(20.2)$ \\
\hline Tedarikçi zinciri ilişskileri & $28(35.4)$ & $18(22.7)$ & $10(12.6)$ \\
\hline Yeni iş firsatları & $55(69.6)$ & $36(45.6)$ & $19(24)$ \\
\hline İşçi ve çalışan eğitimleri & $29(36.7)$ & $21(26.6)$ & $8(10.1)$ \\
\hline Enerji verimliliği - Ekoverimlilik & $49(62.1)$ & $28(35.4)$ & $21(26.5)$ \\
\hline Atık yönetimi & $31(39.2)$ & $23(29)$ & $8(10.1)$ \\
\hline Yeni pazar firsatları elde etme & $3(0.3)$ & $2(0.2)$ & $1(0.1)$ \\
\hline
\end{tabular}

Tablo 2'de mermer işletmelerinin (küme üyesi olma/olmama) \%92.4'ünün iş sağlığı ve iş güvenliği, \%69.6'sının yeni iş fırsatları, \%63.2'sinin çevre kirliliğinin azaltılmas1, \%62'sinin enerji verimliliği-ekoverimlilik ve \%59.4'ünün fuar katılımı konularında diğer kurum/kuruluş/işletme (ler) ile işbirliği içinde olduğu görülmektedir. Genel olarak küme üyesi olan işletmelerin konuların tamamında üye olmayanlara göre daha fazla işbirliği içinde olduğu görülmektedir.

\section{Tablo 3. Sosyal Ve Çevresel Performansın Artırılması Için Işbirliği Yapılan Kurumlara Göre Dağılım}

\begin{tabular}{|l|c|c|c|}
\hline $\begin{array}{c}\text { Sosyal ve Çevresel performansın } \\
\text { artırılması için işbirliği yapılan } \\
\text { kurumlar }\end{array}$ & $\begin{array}{c}\text { Küme üyesi } \\
\text { olma/olmama } \\
\mathbf{f}(\mathbf{\%})\end{array}$ & $\begin{array}{c}\text { Küme üyesi } \\
\mathbf{f}(\mathbf{\%})\end{array}$ & $\begin{array}{c}\text { Küme üyesi olmayan } \\
\mathbf{f}(\mathbf{\%})\end{array}$ \\
\hline KOSGEB & $28(35.4)$ & $15(18.9)$ & $13(16.5)$ \\
\hline Çevre Bakanlığı & $24(30.3)$ & $17(21.5)$ & $7(0.8)$ \\
\hline Ticaret ve Sanayi Odaları & $34(43)$ & $24(30.3)$ & $10(12.6)$ \\
\hline Üniversiteler & $19(24)$ & $11(13.9)$ & $8(10.1)$ \\
\hline Türk Patent Enstitüsü & $9(11.3)$ & $4(0.5)$ & $5(0.6)$ \\
\hline Tedarikçiler & $16(20.2)$ & $11(13.9)$ & $5(0.6)$ \\
\hline Kalkınma Ajansları & $12(15.1)$ & $9(11.3)$ & $3(0.3)$ \\
\hline
\end{tabular}

İşletmelerin sosyal ve çevresel performanslarını artırmak için işbirliği yaptığ kurumların \%43'ünü Ticaret ve Sanayi Odaları, \%35.4'ünü KOSGEB, \%30.3'ünü Çevre Bakanlığı ve \%24'ünü üniversiteler ve \%20.2'sini tedarikçiler oluşturmaktadır.

Mermer işletmelerinin sürdürülebilirlik uygulamalarına yönelik değerlendirmelerinin, küme üyesi olma/olmama durumuna göre karşılaştırması Ttestiyle yapılmış ve ilgili hipotezler aşağıda verilmiştir (Tablo 4).

İşletmelerin çevresel etkileri azaltmak için yürüttüğü faaliyetlerde küme üyesi olma/olmama durumlarına göre bir farklılığın olup olmadığına ilişkin hipotezler: 
Ho: Kümelenme içinde yer alan işletmelerin ürün, üretim ve diğer uygulamalarının neden olduğu çevresel etkileri azaltmak için yürüttüğü faaliyetlerde, dışarıda kalan firmalara göre anlamlı bir farklılık yoktur.

H1: Kümelenme içinde yer alan işletmelerin ürün, üretim ve diğer uygulamalarının neden olduğu çevresel etkileri azaltmak için yürüttüğü faaliyetlerde, dışarıda kalan firmalara göre anlamlı bir farklılık vardır.

İşletmelerin sosyal performansı artırma yönündeki faaliyetlerinde küme üyesi olma/olmama durumlarına göre bir farklılığın olup olmadığına ilişkin hipotezler:

Ho: Kümelenme içinde yer alan işletmelerin sosyal performansı artırma yönündeki faaliyetlerinde dışarıda kalan firmalara göre anlamlı bir farklılık yoktur.

H1: Kümelenme içinde yer alan işletmelerin sosyal performansı artırma yönündeki faaliyetlerinde dışarıda kalan firmalara göre anlamlı bir farklılık vardır.

$\mathrm{Bu}$ araştırmada ANOVA analizleri için sosyal bilimlerde genel olarak kabul görmüş p değeri için 0.05 anlam düzeyi kabul edilmiştir. Eğer p değeri 0.05 'ten küçükse $(\mathrm{p}<0.05)$ sonuç istatistiksel olarak anlamlı kabul edilmiş, büyükse $(\mathrm{p}>0.05)$ ilişkinin istatistiksel olarak anlamlı olmadığ kabul edilmiştir.

Tablo 4. İşletmelerin Çevresel Ve Sosyal Duyarlılıklarının Kümede Yer Alma Durumuna Göre Karşılaştırılması

\begin{tabular}{|c|c|c|c|c|c|}
\hline & $\begin{array}{ll}\text { Üyesi } & \text { Küme } \\
\end{array}$ & $\mathbf{N}$ & Ort & SS & p \\
\hline \multirow{2}{*}{ Çevresel } & \multirow{2}{*}{$\begin{array}{l}\text { Evet } \\
\text { Hayır }\end{array}$} & 45 & 3.26 & 0.76 & \multirow{2}{*}{0.004} \\
\hline & & 34 & 2.62 & 1.14 & \\
\hline \multirow{2}{*}{ Sosyal } & Evet & 45 & 3.07 & 0.68 & \multirow{2}{*}{0.033} \\
\hline & Hayır & 34 & 2.59 & 1.23 & \\
\hline
\end{tabular}

Tablo 4'deki analiz sonuçlarına göre işletmelerin çevresel etkilerini azaltmak için yürüttügü faaliyetlerde küme üyesi olma/olmama durumlarına göre karşılaştırmasında $(\mathrm{p}=0.004<0,05)$ Ho hipotezi red edilir. Yani küme üyesi olan mermer işletmeleri ile olmayan işletmeler arasında anlamlı bir farklılık vardır.

İşletmelerin sosyal performansı artırma yönündeki faaliyetlerinde küme üyesi olma/olmama durumlarına göre karşılaştırmasında $(\mathrm{p}=0.033<0,05)$ Ho hipotezi red edilir. Kısaca, küme üyesi işletmeler ile olmayan işletmeler arasında anlamlı bir farklılık vardir.

Tablo 5. Çevresel Faaliyetlere Ilişkin Frekans Dağılımı Ve Yüzdesi

\begin{tabular}{|c|c|c|c|c|c|c|c|c|c|}
\hline \multirow{3}{*}{ Maddeler } & \multirow[b]{3}{*}{ Küme } & \multicolumn{5}{|c|}{ Etki Düzeyi } & \multirow[b]{3}{*}{ ort } & \multirow[b]{3}{*}{ SS } & \multirow[b]{3}{*}{ p } \\
\hline & & Hic & $\mathbf{A z}$ & Orta & Cok & Tam & & & \\
\hline & & $\%$ & $\%$ & $\%$ & $\%$ & $\%$ & & & \\
\hline \multirow{2}{*}{ 1. EMAS belgesi sahipliği } & Evet & 24.4 & 17.8 & 53.3 & 2.2 & 2.2 & 2.40 & 0.96 & \multirow{2}{*}{0.000} \\
\hline & Hayır & 64.7 & 11.8 & 8.8 & 8.8 & 0.0 & 1.50 & 1.05 & \\
\hline \multirow{2}{*}{ 2. ISO 14001 belgesi sahipliği } & Evet & 24.4 & 11.1 & 48.9 & 13.3 & 2.2 & 2.58 & 1.08 & \multirow{2}{*}{0.005} \\
\hline & Hayır & 58.8 & 8.8 & 14.7 & 11.8 & 2.9 & 1.82 & 1.27 & \\
\hline \multirow{2}{*}{$\begin{array}{l}\text { 3. Çevresel etkileri azaltmak için enerji } \\
\text { tasarrufu çalışmaları }\end{array}$} & Evet & 13.3 & 8.9 & 26.7 & 28.9 & 22.2 & 3.38 & 1.30 & \multirow{2}{*}{0.075} \\
\hline & Hayır & 38.2 & 2.9 & 14.7 & 29.4 & 14.7 & 2.79 & 1.57 & \\
\hline \multirow{2}{*}{$\begin{array}{l}\text { 4. Atık azaltımı ve geri dönüşüm } \\
\text { faaliyetlerini önemseme }\end{array}$} & Evet & 6.7 & 6.7 & 26.7 & 37.8 & 22.2 & 3.62 & 1.11 & \multirow{2}{*}{0.616} \\
\hline & Hayır & 23.5 & 2.9 & 8.8 & 32.4 & 32.4 & 3.47 & 1.56 & \\
\hline \multirow{2}{*}{$\begin{array}{l}\text { 5. Doğal çevrenin korunması için } \\
\text { çalışmalar yürütme }\end{array}$} & Evet & 6.7 & 11.1 & 26.7 & 40.0 & 15.6 & 3.47 & 1.10 & \multirow{2}{*}{0.374} \\
\hline & Hayır & 23.5 & 8.8 & 11.8 & 35.3 & 20.6 & 3.21 & 1.49 & \\
\hline \multirow{2}{*}{$\begin{array}{l}\text { 6. Çevre dostu tedarikçilerin } \\
\text { araştırılması }\end{array}$} & Evet & 24.4 & 15.6 & 37.8 & 11.1 & 11.1 & 2.69 & 1.28 & \multirow{2}{*}{0.140} \\
\hline & Hayır & 41.2 & 17.6 & 11.8 & 20.6 & 5.9 & 2.24 & 1.42 & \\
\hline \multirow{2}{*}{ 7. Gerekli yasal mevzuata uygunluk } & Evet & 2.2 & 8.9 & 33.3 & 28.9 & 26.7 & 3.69 & 1.04 & \multirow{2}{*}{0.100} \\
\hline & Hayır & 26.5 & 2.9 & 17.6 & 29.4 & 23.5 & 3.21 & 1.53 & \\
\hline
\end{tabular}




\begin{tabular}{|l|l|c|c|c|c|c|c|c|c|}
\hline $\begin{array}{l}\text { 8. Yeni ürün ve hizmet geliştirme } \\
\text { sirasında çevresel etkileri göz önüne } \\
\text { alma }\end{array}$ & Evet & 4.4 & 11.1 & 28.9 & 26.7 & 28.9 & 3.64 & 1.15 & \\
\cline { 2 - 10 } & Hayır & 32.4 & 8.8 & 5.9 & 35.3 & 14.7 & 2.82 & 1.62 & \\
\hline $\begin{array}{l}\text { 9. Ürün ve hizmetlerinin çevresel etkileri } \\
\text { ile ilgili toplumu bilgilendirme }\end{array}$ & Evet & 6.7 & 6.7 & 35.6 & 33.3 & 17.8 & 3.49 & 1.08 & \multirow{0}{0.000}{} \\
\cline { 2 - 10 }$n$ & Hayır & 44.1 & 5.9 & 8.8 & 32.4 & 5.9 & 2.41 & 1.54 & \\
\hline \multirow{2}{*}{ 10. Üretim sonu kirlilikle mücadele } & Evet & 6.7 & 2.2 & 28.9 & 40.0 & 22.2 & 3.69 & 1.06 & \multirow{0}{*}{$\mathbf{0 . 0 0 3}$} \\
\cline { 2 - 9 } & Hayır & 38.2 & 2.9 & 11.8 & 26.5 & 17.6 & 2.74 & 1.68 & \\
\hline
\end{tabular}

Analiz sonucunda örneklemdeki işletmelerin çevreye olumsuz etkilerin azaltılmasına yönelik değerlendirmelerinde EMAS ve ISO 14001 belgesi sahipliği, yeni ürün ve hizmet geliştirme sırasında çevresel etkileri göz önüne alma, ürün ve hizmetlerinin çevresel etkileri ile ilgili yerel halk, tedarikçiler ve müşterilere karşı açık ve doğru bir bilgi kaynağı olma ve üretim gerçekleştikten sonra kirlilikle mücadele yolunu benimseme açısından küme üyesi olan ve olmayan işletmeler arasında istatistiksel olarak anlamlı bir fark bulunmuştur $(\mathrm{p}<0.05)$. Tablo 5 'deki ortalamalara göre söz konusu farklılıkları içeren maddelerin tamamında küme üyesi olan işletmelerin ortalama puanları küme üyesi olmayanlara göre daha yüksek bulunmuştur. Bu da ilgili maddelerin, küme üyesi olan işletmeler tarafından ürün, üretim ve diğer uygulamaların neden olduğu çevresel etkileri minimize etmede en etkili faktörler olarak görüldüğünü göstermektedir. Diğer uygulamalara yönelik anlamlı bir farklılık bulunmamıştır ( $\mathrm{p}>0,05)$.

Tablo 6. Sosyal Faaliyetlere Ilişsin Frekans Dağılımı Ve Yüzdesi

\begin{tabular}{|c|c|c|c|c|c|c|c|c|c|}
\hline \multirow{3}{*}{ Maddeler } & \multirow[b]{3}{*}{ Küme } & \multicolumn{5}{|c|}{ Etki Düzeyi } & \multirow[b]{3}{*}{ ort } & \multirow[b]{3}{*}{ SS } & \multirow[b]{3}{*}{ p } \\
\hline & & Hiç & $\mathbf{A z}$ & Orta & Çok & Tam & & & \\
\hline & & $\%$ & $\%$ & $\%$ & $\%$ & $\%$ & & & \\
\hline \multirow{2}{*}{ 1. OHSAS 18001 belgesi sahipliği } & Evet & 22.2 & 35.6 & 31.1 & 8.9 & 2.2 & 2.33 & 1.00 & \multirow{2}{*}{0.297} \\
\hline & Hayır & 47.1 & 14.7 & 14.7 & 17.6 & 2.9 & 2.06 & 1.32 & \\
\hline \multirow{2}{*}{ 2. SA8000 belgesi sahipliği } & Evet & 24.4 & 28.9 & 37.8 & 8.9 & 0.0 & 2.31 & 0.95 & \multirow{2}{*}{0.124} \\
\hline & Hayır & 55.9 & 11.8 & 8.8 & 17.6 & 2.9 & 2.06 & 1.32 & \\
\hline \multirow{2}{*}{ 3. AA1000 belgesi sahipliği } & Evet & 28.9 & 26.7 & 28.9 & 15.6 & 0.0 & 2.31 & 1.06 & \multirow{2}{*}{0.143} \\
\hline & Hayır & 55.9 & 11.8 & 8.8 & 17.6 & 2.9 & 1.91 & 1.33 & \\
\hline \multirow{2}{*}{$\begin{array}{l}\text { 4. Çalışanlarımızın yerel toplumsal } \\
\text { faaliyetlere katılmasını destekleme }\end{array}$} & Evet & 13.3 & 20.0 & 35.6 & 24.4 & 6.7 & 2.91 & 1.12 & \multirow{2}{*}{0.709} \\
\hline & Hayır & 35.3 & 2.9 & 11.8 & 23.5 & 26.5 & 3.03 & 1.68 & \\
\hline \multirow{2}{*}{$\begin{array}{l}\text { 5.Yerel toplumsal faaliyetler ve } \\
\text { projelere düzenli finansal destek verme }\end{array}$} & Evet & 6.7 & 4.4 & 35.6 & 35.6 & 17.8 & 3.53 & 1.06 & \multirow{2}{*}{0.107} \\
\hline & Hayır & 35.3 & 2.9 & 11.8 & 23.5 & 26.5 & 3.03 & 1.68 & \\
\hline \multirow{2}{*}{$\begin{array}{l}\text { 6. İlgili taraflara işletme değerlerinin } \\
\text { anlatılması }\end{array}$} & Evet & 15.6 & 11.1 & 28.9 & 33.3 & 11.1 & 3.13 & 1.24 & \multirow{2}{*}{0.826} \\
\hline & Hayır & 32.4 & 2.9 & 5.9 & 29.4 & 29.4 & 3.21 & 1.68 & \\
\hline \multirow{2}{*}{ 7. Çalışma koşullarını geliştirme } & Evet & 4.4 & 2.2 & 20.0 & 37.8 & 35.6 & 3.98 & 1.03 & \multirow{2}{*}{0.008} \\
\hline & Hayır & 32.4 & 0.0 & 5.9 & 32.4 & 26.5 & 3.12 & 1.74 & \\
\hline \multirow{2}{*}{$\begin{array}{l}\text { 8. Çalışanların iyi bir iş yaşam dengesi } \\
\text { sağlamasına yardımcı olma }\end{array}$} & Evet & 33.3 & 15.6 & 28.9 & 13.3 & 8.9 & 2.49 & 1.32 & \multirow{2}{*}{0.557} \\
\hline & Hayır & 41.2 & 11.8 & 14.7 & 11.8 & 14.7 & 2.29 & 1.61 & \\
\hline \multirow{2}{*}{ 9. Ayrımcılığa karşı önlem alma } & Evet & 4.4 & 4.4 & 28.9 & 22.2 & 40.0 & 3.89 & 1.13 & \multirow{2}{*}{0.001} \\
\hline & Hayır & 38.2 & 2.9 & 14.7 & 26.5 & 17.6 & 2.82 & 1.60 & \\
\hline \multirow{2}{*}{ 10.Öneri sistemlerinin desteklenmesi } & Evet & 6.7 & 8.9 & 22.2 & 35.6 & 26.7 & 3.67 & 1.17 & \multirow{2}{*}{0.002} \\
\hline & Hayır & 38.2 & 8.8 & 14.7 & 23.5 & 14.7 & 2.68 & 1.55 & \\
\hline \multirow{2}{*}{$\begin{array}{l}\text { 11. Çalışanlar ile periyodik toplantılar } \\
\text { yapma }\end{array}$} & Evet & 6.7 & 15.6 & 28.9 & 28.9 & 20.0 & 3.40 & 1.18 & \multirow{2}{*}{0.438} \\
\hline & Hayır & 32.4 & 5.9 & 8.8 & 20.6 & 32.4 & 3.15 & 1.71 & \\
\hline \multirow{2}{*}{ 12. Yerel halka eğitim firsatı sunma } & Evet & 15.6 & 17.8 & 28.9 & 17.8 & 20.0 & 3.09 & 1.35 & \\
\hline & Hayır & 44.1 & 8.8 & 26.5 & 11.8 & 8.8 & 2.32 & 1.39 & 0.016 \\
\hline & Evet & 13.3 & 15.6 & 17.8 & 37.8 & 15.6 & 3.27 & 1.29 & \\
\hline el halkla & Hayır & 44.1 & 5.9 & 20.6 & 20.6 & 8.8 & 2.44 & 1.46 & 0 \\
\hline 14. Yerel tedarikçilerden satın almayı & Evet & 40.0 & 4.4 & 15.6 & 24.4 & 15.6 & 2.71 & 1.58 & \\
\hline destekleme & Hayır & 44.1 & 5.9 & 29.4 & 5.9 & 14.7 & 2.41 & 1.48 & 94 \\
\hline
\end{tabular}

Mermer işletmelerin sosyal uygulamalara yönelik değerlendirmelerinde çalışanların sağlık ve güvenliğini sağlamak için çalışma koşullarının geliştirilmesini sağlama, işe alım sırasında ve sonrasında ayrımcılığın tüm şekillerine karşı önlem alma, çalışanların kararlara katılımını sağlayabilmek için öneri sistemini destekleme, yerel 
halktan insanlara eğitim fırsatları sunma ve tartışmalı, hassas veya işletme menfaatine aykırı konularda yerel halkla açık bir diyaloga sahip olma açısından küme üyesi olan ve olmayan işletmeler arasında istatistiksel olarak anlamlı bir fark bulunmuştur $(p<0.05)$. Tablo 6'daki ortalamalara göre söz konusu farklılıkları içeren maddelerin tamamında küme üyesi olan işletmelerin ortalama puanları, küme üyesi olmayanlara göre daha yüksek bulunmuştur. $\mathrm{Bu}$ da ilgili maddelerin, küme üyesi olan işletmeler tarafindan sosyal performansı arttırmada en etkili faktörler olarak görüldüğünü göstermektedir. Diğer sosyal uygulamalara yönelik anlamlı bir farklılık bulunmamıştır $(p>0,05)$.

\section{Tartışma ve Sonuç}

Kümelenme yaklaşımı diğer kurum ve kuruluşlarla işbirliğini gerektirmektedir. $\mathrm{Bu}$ çerçevede, küme üyesi işletmelerin büyük çoğunluğunun çevre kirliliğinin azaltılması, su kullanımı ve yönetimi, enerji verimliliği, atık yönetimi, yenilikçilik, yeni iş firsatları, işçi ve çalışan eğitimleri, iş sağlı̆̆ ve güvenliği, yetişmiş insan kaynağının sağlanması ve fuar katılımı gibi sürdürülebilirlik ile ilgili konularda işbirliği içinde çalıştı̆g 1 tespit edilmiştir. "İş săgllğ işletmelerin neredeyse tamamı (\%92.4) tarafından işbirliği içinde olunan başlıklardan biri olarak görülmüştür. Üye işletmelerin \%95.5'i bu başlığ destekler şsekilde "çalışanların sağlık ve güvenliğini sağlamak için çalışma koşullarının geliştirilmesini" sosyal performansın arttırılmasında etkili faktörlerden biri olarak görmüştür. Ayrıca küme üyesi işletmelerin \%80'nin “yeni iş firsatlart” konusunda diğer işletmelerle iş birliği içinde olması sevindirici bir orandır. Çünkü kümelenme ile ticari ortamdaki bilgi dolaşımı sağlanıp yaşanabilecek ticari başarısızlıkların maliyetleri en aza indirgenebilmektedir. Böylece, işletmeler bölgesel bilgi dolaşımından faydalanarak, iş fırsatlarını değerlendirebilmektedir. Maalesef "inovasyon çalışmaları" küme üyesi işletmelerin ancak \%31'i tarafından diğer kurumlarla işbirliğine konu olmuştur. $\mathrm{Bu}$ durum mermer kümelenmesinin, yenilikçiliğin ve Ar-Ge faaliyetlerinin teşvik edilmesi gibi önemli bir misyonu yerine getiremediğini göstermektedir.

Sürdürülebilir kalkınmada önemli bir paya sahip ve toplumun ayrılmaz bir parçası olan KOBİ'lerin, çevresel ve sosyal performanslarını geliştirilmesi EMAS, ISO 14001, OHSAS 18001, SA8000 ve AA1000 gibi formel yönetim sistemlerini uygulaması ile mümkündür. Bu yönetim sistemleri politikalar, prosedürler ve uygulamalar aracılığıyla çevresel etkilerin kontrolünü sağlamaktadır (Hillary, 2004, s.562). Araştırma sonuçlarına göre, küme üyesi KOBİ niteliğindeki mermer işletmelerinin ancak \%8.9'nun ISO 14001'e, \%11.4'nün ise OHSAS 18001'e sahip olduğu, formel yönetim sistemlerinin göstergesi olan diğer belgelere (SA8000, AA1000, EMAS gb.) ise hiçbir işletmenin sahip olmadığı görülmüştür. Literatürdeki konuyla ilgili çalışmalar da, araştırma bulgularını destekler niteliktedir. Gittikçe önem kazanan bu belgelerden ISO 14001'e, Uluslararası Standartlar Organizasyonu (ISO)'nun 2007 sonu verilerine göre 140 ülkede 154.000'nin üzerinde kurum sahiptir (Heras ve Arana, 2010, s.1). Avrupa Komisyonu'nun 28 Avrupa Birliği ülkesinde 11207 KOBİ'ye Eylül 2013'de "KOBİ'ler, Kaynak Verimliliği ve Yeşil Pazarlar" başlığıyla gerçekleştirdiği araştırmanın sonuçlarına göre ise KOBI'lerin üçte ikisinden fazlası (\%67) çevre yönetim sistemlerini kullanmadıklarını belirtmiş, \%43'ü ulusal ya da bölgesel sistemleri tercih ettiklerini, \%36's1 ise ISO 14001'e sahip olduğunu bildirmiştir (Eurobarometer, 2013, s.53). Ayrıca yapılan araştırmalar KOBI'lerin çevresel ve sosyal sorumluluk ile ilgili konularda daha çok informel uygulamalara yoğunlaştığını göstermektedir. Sekiz farklı Latin Amerika ülkesinde 1300 KOBİ'yle yapılan bir araştırmada, KOBI'lerin 
çalışanlara kredi sağlama, yerel topluluk ve dini kurumlara bağış yapma gibi informel uygulamaları daha çok tercih ettiği tespit edilmiştir (Jeppesen vd., 2012, s.45). İtalyan Ticaret, Sanayi, Zanaat ve Tarım Odaları Birliği (Italian Union of Chambers of Commerce, Industry, Craft and Agriculture)'nin 2003 yılında yaptığı bir başka araştırmada da, küçük ölçekli işletmelerin para bağışı, kalite belgelendirme çalışmaları ve çalışanların lehine uygulamalarla ilgili olduğu belirlenmiştir (Borga vd., 2009, s.164).

Küme üyesi mermer işletmelerinin üretim ve diğer uygulamaların neden olduğu çevresel etkileri minimize etmede EMAS ve ISO14001 belgesi sahipliği, yeni ürün ve hizmet geliştirme sırasında çevresel etkileri göz önüne alma yani temiz teknolojiye yatırım, ürün ve hizmetlerinin çevresel etkileri ile ilgili yerel halk, tedarikçiler ve müşterilere karşı açık ve doğru bir bilgi kaynağı olma ve üretim gerçekleştikten sonra kirlilikle mücadele yolunu benimsemeyi en etkili faktörler olarak gördüğü tespit edilmiştir. Küme üyesi işletmeler temiz teknolojiye yatırımı çevresel etkileri minimize etmede etkin bir faaliyet olarak görürken aynı zamanda üretim sonu kirlilikle mücadeleyi de gerekli görmektedir. Oysa ki temiz teknoloji, kirleticilerin oluşumunu kaynağında ve bütünsel (entegre) tedbirlerle önleme felsefesine dayanmaktadır (Demirer, 2001, s.214). Mermer işletmelerinin çevresel etkileri minimize etmede etkili gördüğü bu faktörler değerlendirildiğinde, formel standartlar ve çevresel konularda ki bilgi düzeyi yetersizliği dikkat çekmektedir. Ayrıca, ürün ve hizmetlerin çevresel etkilerine yönelik yerel halk, tedarikçiler ve müşterilerin bilgilendirilmesi etkili görülen bir başka faktördür. Mermer sektöründe yapılan işin niteliği ve yasal zorunluluk gereği çevresel etkiler konusunda bölge halkının bilinçlendirilmesi gerekmektedir. Küme üyesi işletmelerin bir ihtisas organize sanayi bölgesinde yer alması bu konuya olan duyarlılıklarının kaynağı olarak görülebilir.

İşletmelerin sosyal performanslarına yönelik faaliyetleri değerlendirildiğinde, küme üyesi işletmelerin neredeyse tamamı iş sağlığ ve güvenliği ile işçi ve çalışan eğitimleri konularında diğer kurum ve kuruluşlarla işbirliği içinde olduğunu belirtmiştir. Ayrıca ayrımcılığın tüm şekillerine karşı önlem alma, çalışma koşullarının geliştirilmesini ve çalışanların kararlara katılımını sağlama sosyal performansın geliştirilmesinde etkili faktörler olarak görülmüştür.

\section{Kaynakça}

ACCA (2012). "Embedding Sustainability in SMEs", ww.accaglobal.com/globalforums (Erişim tarihi: 20.12.2013)

Bayülken, Y. ve Kütükoğlu, C. (2012). "Küçük ve Orta Ölçekli Sanayi İşletmeleri”, TMMOB, Makina Mühendisleri Odası Oda Raporu, Genişletilmiş 4. Baskı, Yayın No: $\mathrm{MMO} / 583$.

Borga vd. (2009). Sustainability Reporting In Small Enterprises: An Italian Perspective, Business Strategy and the Environment, Volume 18, Issue 3:162-176.

Chang, H.C., Tsai, C.L., Henderson, S.(2012). "How Industrial Clusters and Regional Innovation Systems Impact the Knowledge Innovation Within the Taiwanese Science-Based Parks Firms?", New Research on Knowledge Management Applications and Lesson Learned, Intech China. 
Demirer G.N. (2001). Temiz Üretim/Kirlilik Önleme Kavramı ve Çevre Mühendisliği Eğitimi, 4. Ulusal Çevre Mühendisliği Kongresi, TMMOB Çevre Müh. Odası, 710 Kasim: 212-221.

Eroğlu, O. ve Yalçın, A. (2013). "Kümelenme ve Rekabetçilik İlişkisi: Kavramsal Bir İnceleme", Afyon Kocatepe Üniversitesi, İ̈BF Dergisi, C. 15, S. 2:175-193.

EUROBAROMETER (2013). Smes, Resource Efficiency and Green Markets Report, http://Ec.Europa.Eu/Public_Opinion/Flash/F1_381_En.Pdf (Erişim tarihi: 09.01.2014).

Foot D.K. \& Ross, S. (2004). Social Sustainability. In Teaching Business Sustainability, Volume 1, From Theory to Practice, Galea, C.(ed.). Greenleaf: Sheffield; 107125.

Gürlük, S. (2010). “Sürdürülebilir Kalkınma Gelişmekte Olan Ülkelerde Uygulanabilir mi?”, Eskişsehir Osmangazi Üniversitesi İİBF Dergisi, Ekim, 5(2), 85-99.

Hahn, T. \& Scheermesser, M. (2006). Approaches to Corporate Sustainability among German Companies, Corporate Social Responsibility and Environmental Management, Vol. 13: 150-165.

Has, Z. (2013). Kümelenme Teorisi ve Porter Elmas Modeli, İzmir Ticaret Odası, Kasim.

Hemel, C. \& Cramer, J. (2002). Barriers and Stimuli for Ecodesign in SMEs, Journal of Cleaner Production, Vol.10: 439-453.

İMKB (2011). Türk İş Dünyası'nda Sürdürülebilirlik Uygulamaları Değerlendirme Raporu, Eylül. http://www.tbcsd.org/ (Erişim tarihi: 25.11.2015).

İMMIB (2014). Maden Sektörü İhracatının Değerlendirilmesi, http://www.immib.org.tr/tr/birliklerimiz-istanbul-maden-ihracatcilari-birligimaden-sektoru-ihracatinin-degerlendirilmesi.html

Jeppesen, S., Kothuis, B. \& Ngoc Tran, A. (2012). Corporate Social Responsibility and Competitiveness for SMEs in Developing Countries: South Africa and Vietnam, FOCALES 16.

Lawrence vd. (2006). Sustainability Practices of SMEs: The Case of NZ, Business Strategy and the Environment, Vol. 15: 242-257.

Pelit, E., Baytok, A. ve Soybal1, H.H. (2015). "Sürdürülebilir Turizm Mi? Turizmde Sürdürülebilirlik Mi? Kavramsal Bir Tartışma”, Gümüşhane Üniversitesi, Sosyal Bilimler Elektronok Dergisi, Sayı. 14, Aralık. http://sbedergi.gumushane.edu.tr/ Makaleler/1339703799_8ElbeyiPelit\%20-\%2010.17823gusb.220.pdf (Erişim Tarihi: 10.01 .2016$)$

Porter, M.E. (1998). "Clusters and the New Economics of Competition", Harvard Business Review, https://hbr.org/1998/11/clusters-and-the-new-economics-ofcompetition (Erişim Tarihi: 10.11.2015)

Resmi Gazete "Organize Sanayi Bölgeleri Uygulama Yönetmeliği”, 22.08.2009, Say1: 27327, http://mevzuat.basbakanlik.gov.tr/Metin.Aspx?MevzuatKod=7.5.13352\& MevzuatIliski $=0 \&$ sourceXmlSearch $=$ organize $($ Erişim Tarihi: 10.08 .2015$)$ 
Sharma, S. \& Ruud, A. (2003). Editorial on the Path to Sustainabilty: Integrating Social Dimensions Into the Research and Practice of Environmental Management, Business Strategy and the Environment, 12: 205-214.

The World Business Council for Sustainable Development (WBCSD) (2004). Promoting Small and Medium Enterprises for Sustainable Development, Development Focus Area, Issue Brief.

Tuna, Ö. (2014). Kurumsal Sürdürülebilirlik Yaklaşım ve Uygulamaları: KOBİ'lere Yönelik Bir Araştırma, Afyon Kocatepe Üniversitesi, Sosyal Bilimler Enstitüsü, Doktora Tezi.

Ural, A. ve Kılıç, İ. (2013) Bilimsel Araştırma Süreci ve SPSS ile Veri Analizi, Detay yayınc1l1k, 4.Bask1, Ankara.

WRAP (2011). Increasing SME Recycling, Summary Report, http://www.wrap.org.uk/sites/files/wrap/SME_Recycling___Summary_ Report.pdf (Erişim tarihi: 09.10.2015)

Yardımcı, A. (2014). "Sanayi Kümelenmelerinde Nash Dengesi: Kavramsal Bir İnceleme", Endüstri Mühendisliği Dergisi, Cilt. 26, Sayı. 1: 22-30

Yu, J. (2004). Building a Sustainable Business in Chinese Small and Medium-sized Enterprises (SMEs), Imperial College London Faculty of Life Sciences, Department of Environmental Science \& Technology. 


\title{
The Effect of Clustering on Sustainability Practices: A Study on Turkish Marble Enterprises
}

\author{
Özlem TUNA \\ Afyon Kocatepe University \\ Afyon Health School \\ Afyonkarahisar, Turkey \\ ozltuna@hotmail.com
}

\section{Extensive Summary}

\section{Introduction}

Sustainability with environmental, social and economic dimensions means that enterprises can understand risks and opportunities and accordingly rearrange their activities, products and services, as well as their business models and whole processes when necessary. These arrangements intended for sustainability require enterprises to make significant capital and expertise investments, have long term business plans, and train managers and employees for the language concerning sustainability to be understood. Sustainability, which requires long time and effort, can be facilitated with clustering (Has, 2013, p.2), which provides advantages such as geographical, cultural and corporate proximity to enterprises, special access to other enterprises, closer affiliations, easy access to knowledge, and obtaining strong incentives. Therefore, it has become important to understand characteristics of SMEs, which constitute the main stakeholder of clusters, and increase their qualifications for sustainable development.

According to OECD data, well managed and healthy structures of SMEs, which comprise $95 \%$ of all enterprises and $60 \%$ of all employees, is considered to be a significant source in terms of employment and development on account of their contribution to social stability and general tax revenues (WBCSD, 2004, p. 2). 99.6\% of $2,406,720$ enterprises that operate in our country are at a magnitude that is eligible for the SME definition of European Union. Among these enterprises, the number of individuals employed per workplace of mining and quarrying activity fields (average scale size) is 34.3 (Bayulken and Kutukoglu, 2012, p. 16). 83.6\% of enterprises subject to the study comprise of SMEs, supporting this data. Therefore, the study intended to identify approaches of marble enterprises with SME characteristics, which are and are not members of clusters, to corporate sustainability practices. In this context, a qualitative study was conducted on 79 marble enterprises with SME characteristics, which operate in Iscehisar Specialized OIZ as members of a cluster and which operate in various provinces without being members of any cluster.

\section{Method}

The study was conducted in Iscehisar Specialized OIZ as well as on enterprises, which own marble quarries and make production in various provinces, without being members of any cluster. In this context, surveys conducted with a total of 79 marble enterprises, 45 of which operate in Iscehisar Specialized OIZ and 34 of which operate in various provinces of our country, were evaluated.

The study was conducted from May to October 2015. During the research, a survey with two sections was used as the data collection technique. Surveys were 
prepared in both manual format and digital format, and they were completed by senior managers. The study made use of the sectorial adaptation based on literature, utilizing scales implemented during studies by Hahn and Scheermesser (2006) on German enterprises; Yu (2004) on SMEs operating in China and Istanbul Stock Exchange (2011) on enterprises that were members of Istanbul Stock Exchange, as well as the scale generated by Tuna (2014) by means of validity and reliability studies. During the research, data obtained by means of the survey were analyzed with SPSS for Windows Software Package. Data obtained from the survey study, conducted on enterprises in Iscehisar Specialized OIZ and various provinces, were subjected to statistical analyses such as frequency, percentage, arithmetic mean, standard deviation and t-test according to the main scheme of the study. Achieved statistical values were evaluated with comparative analyses and hypotheses, comprising the foundations of the study, were tested.

\section{Results}

Sustainability practices of enterprises wee compared by means of t-test according to whether they are members of a cluster; upon which Ho hypotheses were rejected and H1 hypotheses were accepted according to analysis results. In other words, a significant distinction was found in activities, conducted by enterprises for the purpose of reducing environmental influences and increasing social performance, between marble enterprises that were and were not members of a cluster.

During evaluations on reduction of negative influences on environment by enterprises in the sample group, a statistically significant difference $(p<0.05)$ was found between establishment that were and were not members of a cluster, in terms of holding EMAS and ISO 14001 certificates, being an explicit and accurate source of information for local population, suppliers and customers concerning the environmental influences of their products and services, and adoption of combating pollution after production is made.

During evaluations on social practices of marble enterprises, a statistically significant difference $(p<0.05)$ was found between establishment that were and were not members of a cluster, in terms of ensuring improvement of working conditions for the purpose of ensuring health and safety of employees, taking measures against all kinds of discrimination during and after recruitment, supporting suggestion system in order to ensure participation of employees in decision-making, providing individuals in local population with educational opportunities, and having an open dialogue with local population concerning controversial and delicate issues as well as issues that are unfavorable for the establishment. In conclusion, it was determined that enterprises that were members of a cluster considered the items listed above as the most effective factors in their evaluations intended for reducing negative influences on the environment and increasing social performance.

\section{Discussion and Conclusion}

Clustering approach requires cooperation with other institutions and organizations. In this context, it was determined that a majority of enterprises that were members of a cluster worked in cooperation with other institutions/organizations and enterprises in respect of matters concerning sustainability such as reducing environmental pollution, water utilization and management, energy efficiency, waste 
management, innovation, new business opportunities, worker and employee trainings, occupational health and safety, ensuring qualified labor force, and participation in fairs. "Occupational health and safety" was regarded as one of the co-operational titles by almost all enterprises that were/were not members of a cluster $(92.4 \%)$. 95.5\% of member enterprises considered "improvement of working conditions for the purpose of ensuring health and safety of employees" as one of the factors effective in increasing social performance in furtherance of this title. Furthermore, it is also remarkable that $80 \%$ of enterprises, which were members of a cluster, cooperated with other enterprises in terms of "new business opportunities". On the other hand, "innovation activities" were a matter of cooperation with other enterprises for only $31 \%$ of enterprises that were members of a cluster.

According to results of the study, only $8.9 \%$ of marble enterprises with SME characteristics, which were members of a cluster, held ISO 14001 while only $11.4 \%$ held OHSAS 18001, and none of the enterprises held other certificates (SA8000, AA1000, EMAS etc.) indicating formal management systems. Enterprises that were members of a cluster considered investment in clean technology as a factor influencing minimization of environmental effects; while, at the same time, considered combating pollution due to production to be necessary. However, clean technology is based on the philosophy of preventing generation of pollutants at the source and with integrated measures (Demirer, 2001, p.214). As these factors, considered by marble enterprises to be effective in minimization of environmental influences, and situations of such enterprises are evaluated; the inadequacy of knowledge on formal standards and environmental issues, as well as the lack of sincerity in responses, stand out.

When activities of enterprises regarding their social performances are evaluated, almost all enterprises, which were members of a cluster, stated that they were in cooperation with other institutions and organizations in terms of occupational health and safety, as well as employee trainings. In addition, taking measures against all kinds of discrimination, ensuring improvement of working conditions and participation of employees in decision-making were deemed as factors influencing improvement of social performance. However, as the levels of holding OHSAS $18001(11.4 \%)$ and SA8000 (none of the enterprises hold the certificate) and considering these certificates to be effective, which show the sincerity of enterprises in this regard, are evaluated; it would not be wrong to say that enterprises are inadequate in terms of human rights. 